\title{
APPROACH FOR THE DEVELOPMENT AND APPLICATION OF TARGET PROCESS MODULE SETS
}

\author{
Albers, Albert (1); \\ Wilmsen, Miriam (1); \\ Gericke, Kilian (2) \\ 1: Karlsruhe Institute of Technology; \\ 2: University of Rostock
}

\begin{abstract}
The implementation of agile frameworks, such as SAFe, in large companies causes conflicts between the overall product development process with a rigid linkage to the calendar cycles and the continuous agile project planning. To resolve these conflicts, adaptive processes can be used to support the creation of realistic target-processes, i.e. project plans, while stabilizing process quality and simplifying process management. This enables the usage of standardisation methods and module sets for design processes.

The objective of this contribution is to support project managers to create realistic target-processes through the usage of target-process module sets. These target-process module sets also aim to stabilize process quality and to simplify process management. This contribution provides an approach for the development and application of target-process module sets, in accordance to previously gathered requirements and evaluates the approach within a case study with project managers at AUDI AG $(\mathrm{N}=21)$ and an interview study with process authors $(\mathrm{N}=4)$ from three different companies.
\end{abstract}

Keywords: Design process, Design practice, Case study, Project management, Modular process

\author{
Contact: \\ Wilmsen, Miriam \\ Karlsruhe Institute of Technology (KIT) \\ IPEK Institute of Product Engineering \\ Germany \\ miriam.wilmsen@partner.kit.edu
}

Cite this article: Albers, A., Wilmsen, M., Gericke, K. (2021) 'Approach for the Development and Application of Target Process Module Sets', in Proceedings of the International Conference on Engineering Design (ICED21), Gothenburg, Sweden, 16-20 August 2021. DOI:10.1017/pds.2021.53 


\section{INTRODUCTION}

More and more large companies, such as Ericson, Airbus or Volvo Cars are implementing agile frameworks to improve their product development (Paasivaara et al., 2018; Westerbuhr, 2020; Bergqvist and Gordani Shahri, 2018). Volvo Cars implemented the Scaled Agile Framework (SAFe) throughout the entire organization and focused on the core values: alignment, built-in quality, transparency and program execution (Bergqvist and Gordani Shahri, 2018). Thereby, Volvo Cars implemented a quarterly planning process that contrasts the strict calendar cycles in automotive industry (Denning, 2020). This is one of the major conflicts for large companies, when implementing agile frameworks while having strict product development processes (PEP) that are rigidly linked to the calendar cycles, especially within the automotive industry. To resolve this conflict, the product development process is required to provide flexibility, which enables agile project planning as well as agile working principles. Therefore process models, such as the VDI 2221 (2019a, 2019b) or the iPeM - integrated product development model (Albers et al., 2016b) were created to provide companies an adaptive process framework. Hence, these adaptive process frameworks can be used to restructure the company's product development process to allow agile project planning through the context- and demand specific selection and combination of product development activities. However, these adaptive process frameworks are very generic to suit the demands of various industries, but do not provide a very detailed support for project managers to create a realistic target-process. A target-process is the actual planned execution of a generic reference process, which results from the adaption of the reference process to the specific requirements of the development project and helps the project manager to plan the project (Wilmsen et al., 2020). Thus, there is a demand for an approach that supports project managers to create a realistic target-process that meets the requirements of the project while enabling the adaption of the target-process regarding changing project conditions, to enable agile project planning. Due to the complexity of today's products and therefore product development processes, such an approach can lead to large process management efforts and to a diverging quality of the target-processes. To avoid these issues, the usage of standardisation methods, such as module sets, can simplify the process management through the unification and reuse of process elements while providing individually tailored target-process proposals for project managers.

The objective of this contribution is to support project managers to create realistic target-processes through the usage of target-process module sets. These target-process module sets also aim to stabilize process quality and to simplify process management. As visualised in Figure 1, a target-process module set comprises the existing process knowledge of an organizational unit, similar to VDI 2221 (2019b). The reuse and adaption of existing process elements and their recombination leads to the instantiation and configuration of target-process proposals. These target-process proposals are tailored to the respective development project in order to provide the project manager with the best possible support for project planning.

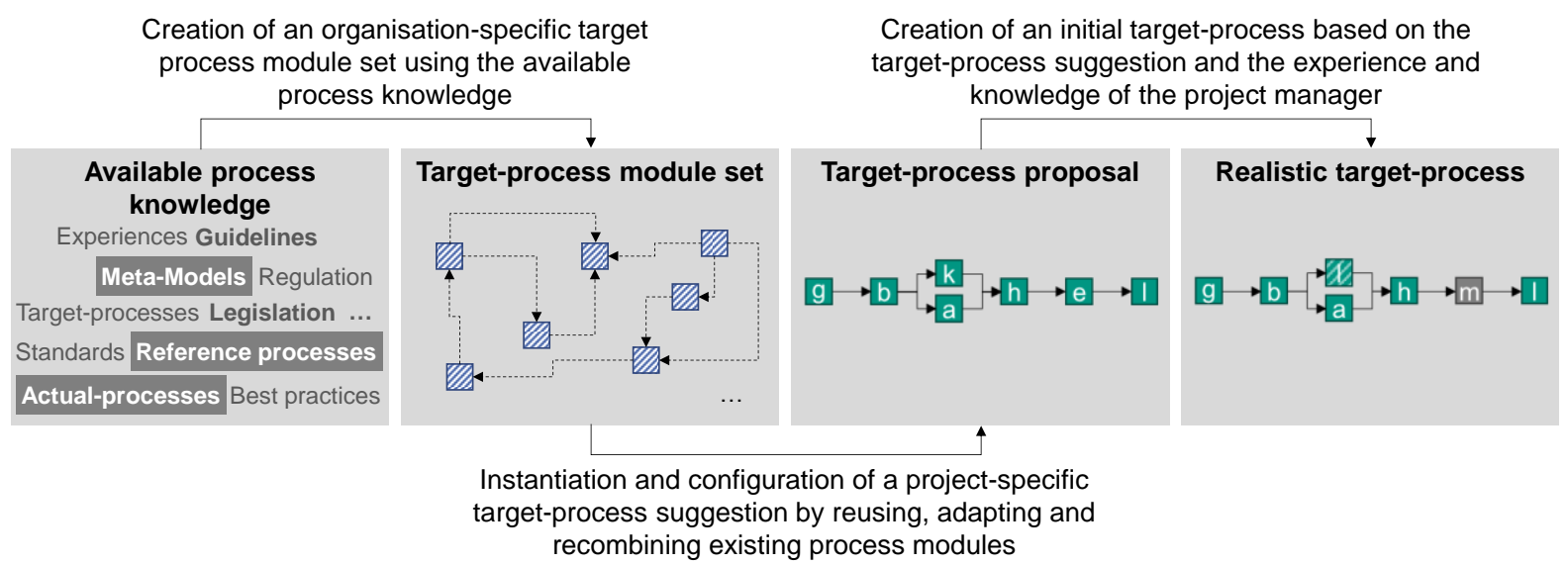

Figure 1. Overview of the coherences of the target-process module set

Based on the objective of this contribution, the following research hypothesis was formulated: "The usage of target-process module sets leads to a simplification of the process management for heterogeneous development projects, while stabilizing the process quality and promotes the creation of realistic target-processes by project managers." 
A preliminary study indicated, that automotive predevelopment departments are organisation units with a high degree of uncertainties and very heterogeneous development projects. Hence, the following research questions focus on automotive predevelopment projects:

1. How should a model for target-process module sets be designed to support project managers in the development of realistic target-processes, while stabilizing the process quality and simplifying process management?

2. To what extent does the usage of target-process module sets promote the creation of realistic target-processes?

3. To what extent does the usage of target-process module sets stabilize process quality and simplify process management?

In terms of this contribution, a target-process is considered as realistic, if it is applicable and feasible with regard to the planned resources and adherence to deadlines or defined milestones. This can be measured retrospectively by the deviation from the actual-process. For a prospective evaluation, it is only possible that an experienced project manager assesses how realistic the target-process is. The field of application of target-process module sets focuses organisational units with a high project divergence, a high dynamic of the environment and a high level of product uncertainty.

\section{STATE OF THE ART}

Adaptive development processes aim to address the demand for design process representations that better fit to the actual-process than most reference processes usually do. Ponn et al. (2004) developed an approach for project managers to build an individual design process based on a modular process toolkit that includes various process steps and corresponding design methods. Meißner and Blessing (2006) support project managers with the context-specific adaption of a design process through defining an adaptive product development methodology. Ponn and Lindemann (2005) present a configurable process module set that is adapted by the characterization of the design situation. Hollauer et al. (2017) developed an adaptable mechatronic engineering design process, which enables a context-dependent adaption of a reference model. Furthermore, Cooper (2016) designed an AgileStage-Gate Hybrid Model to combine the advantages of stage-gate and agile processes. Riesener et al. (2018) developed a framework to support the process-related combination of agile and plan-driven approaches in design projects. Götz and Maier (2007) have generated an adaptive product development process that does not adapt to changing framework conditions in the company, but to the product to be developed. Hallerbach et al. (2008) have developed an approach with an associated IT tool with which the configuration of process variants is to be facilitated by applying context-dependent changes to the basic process. The approach includes so-called context rules, which are assessed as "true" depending on the characteristics of the context factors and are applied to the basic process. It is also possible to reconfigure the process variant while the process is being carried out. In their contribution, Kumar and Yao (2012) push the design and management of flexible process variants of business processes with the help of templates and rules. MacCormack et al. (2001) have developed a flexible process to be used for the development of new products in the software industry. Nunes et al. (2011) have developed a context-dependent approach that is intended to enable dynamic adaptation of business processes in real time. The approach includes computer-based support for dynamic process adaptation through the targeted management of the context. As a result, the suitability of the process instance to the needs and goals of the users and the organization can be checked, new situations can be identified and the understanding of the context and process relation can be further developed. Redding et al. (2009) present the modelling of flexible business processes with the help of business objects. This object-oriented approach enables the modelling of three different flexibility pattern $\mathrm{s}$ in order to model business processes as interactions with business objects.

Due to the high variety of the analysed approaches, a comparison is listed in Table 1 . The adaptive processes are compared regarding their considered process elements and the considered influences for the process adaption. Unfortunately it was not possible to assess every adaptive process in terms of the two dimensions. The comparison of the considered process elements gives insights whether the approach rather focuses on a small excerpt of a process, e.g. only activities or whether the adaptive process incorporates the complexity of a real-world development process through the consideration of multiple process element types. Most of the approaches focus only an extract of available process elements, such as deliverables, tasks or milestones, but do not consider the dependencies of these 
process elements. Some of the approaches consider process modules that consist of a predefined set of process elements. This indicates, that the existing approaches simplify the real-world process, but therefore the process can deviate from the real-world process which would lead to a less realistic target-process. The influence for adaption compares the influence-factors or fields of influence were considered for the process adaption. This gives insights, whether only an excerpt of the actual influence factors on a real-world process were considered or whether a multitude of influence factors was considered. Most of the approaches consider the design project, the design context or the design situation as influence for the process adaption. However, none of the adaptive processes combines all of these areas of influence which can also lead to a less realistic target-process. Another missing aspect is the active usage of available process knowledge, as described in the adaptive process framework of the VDI 2221 (2019a, 2019b), within the respective organization unit, as well as the continuous improvement of the adaptive process using for example documented actual processes and lessons learned. Hence, this contribution provides a model for target-process module sets and a method for their utilization in design practice.

\section{Table 1. Comparison of the adaptive processes}

\begin{tabular}{|c|c|c|}
\hline Literature & Influence for adaption & Process elements \\
\hline Ponn et al. (2004) & Situation & Process modules consisting of: deliverables, activities, methods, aids \\
\hline Meißner and Blessing (2006) & Context & $\begin{array}{l}\text { Process module (includes sub-process. i.e. activity / task to solve a } \\
\text { sub-problem), methods }\end{array}$ \\
\hline Ponn and Lindemann (2005) & Situation, user & Process modules consisting of: deliverables, activities, methods, aids \\
\hline Hollauer et al. (2017) & $\begin{array}{l}\text { Context, initial situation, } \\
\text { optional: product }\end{array}$ & $\begin{array}{l}\text { Phases, activities, methods, product models / documents, interfaces to } \\
\text { other processes }\end{array}$ \\
\hline Cooper (2016) & N/A & Milestones (gates), sprints \\
\hline Riesener et al. (2018) & Constitutive attributes & N/A \\
\hline Götz and Maier (2007) & Product & Deliverables \\
\hline Hallerbach et al. (2008) & Context & N/A (process variants) \\
\hline Kumar and Yao (2012) & N/A & N/A (process variants) \\
\hline MacCormack et al. (2001) & Context & Milestones, phases \\
\hline Nunes et al. (2011) & Context & N/A \\
\hline Redding et al. (2009) & N/A & Tasks, business objects \\
\hline
\end{tabular}

\section{RESEARCH DESIGN}

The research design is based on DRM - Design Research Methodology (Blessing and Chakrabarti, 2009) and is summarized in Table 2.

Table 2. Research design of this contribution

\begin{tabular}{|lll|}
\hline DRM Phase & RQ & Answered in \\
\hline Research clarification & - & Section 1 \& 2 \\
\hline Descriptive study I (DS- I) & - & Wilmsen et al. 2020 \\
\hline Prescriptive study (PS) & RQ 1 & Section 4 \\
\hline Descriptive study II (DS-II) & RQ 2 & Section 5 \\
& RQ 3 & Section 6 \\
\hline
\end{tabular}

Based on the research clarification, the research gap, objective, hypothesis and the three research questions are derived (section 1). A literature review (research clarification) covered different adaptive design processes (section 2). The descriptive study I is published in Wilmsen et al. (2020) and hence not part of this contribution. Based on the needs and requirements identified in DS-I a model for target-process module sets and a corresponding method to utilize target-process module sets is created (RQ 1, PS, section 4). The proposed model and corresponding method is evaluated within two studies. The first study is executed as an application evaluation within different predevelopment departments at AUDI AG (RQ 2, DS-II, section 5). The evaluation investigates the implementation of a target-process module set in these departments, as well as the utilization of the target-process module set by several project managers. Part of the application evaluation is a study of 21 project managers from several predevelopment departments at AUDI AG. During this study, the "think out loud"-method is used and after the application, semi-structured interviews are executed, followed by a short survey to evaluate the strengths and weaknesses of the proposed approach. To protect the privacy of the participants and due to the small number of participants, it is not allowed to gather information on personal data of the participants, such as work experience, age, competencies. The RQ 3 is evaluated through an interview study with 4 process authors from three different automotive OEMs in Germany (DS-II, section 6). 
These process authors were responsible for the development of a reference process within their predevelopment department. The study includes the presentation of the developed approach and a semi-structured interview to identify the advantages, suitable fields of application and improvement potentials of the target-process module set and its application.

\section{MODEL OF A TARGET-PROCESS MODULE SET AND METHOD FOR UTILIZATION IN DESIGN PRACTICE (PS)}

A target-process module set is defined as the quantity of all process elements that follow the corresponding rules, with the objective to instantiate and configure context-specific target-process suggestions with each different quantities of all context-specific work activities. Furthermore, a process module is defined as a process element that can be exchanged by other process elements, which leads to a variation of the context-specific work activities. The definitions of the target-process module set and process modules are based on the definitions of module sets and product modules of VDI 2221 (2019a) and Bursac (2016). A model of such a target-process module set is visualized in Figure 2. This model was further evolved based on a previous prescriptive study within Wilmsen et al. (2019c). The model of the target-process module set includes different types of process modules that can vary in different fields of application. Hence, the scope of the target-process module set is an important aspect of the model. The three types of dependencies describe the rules of the target-process module set. Additionally, the process modules can be classified as mandatory or optional.

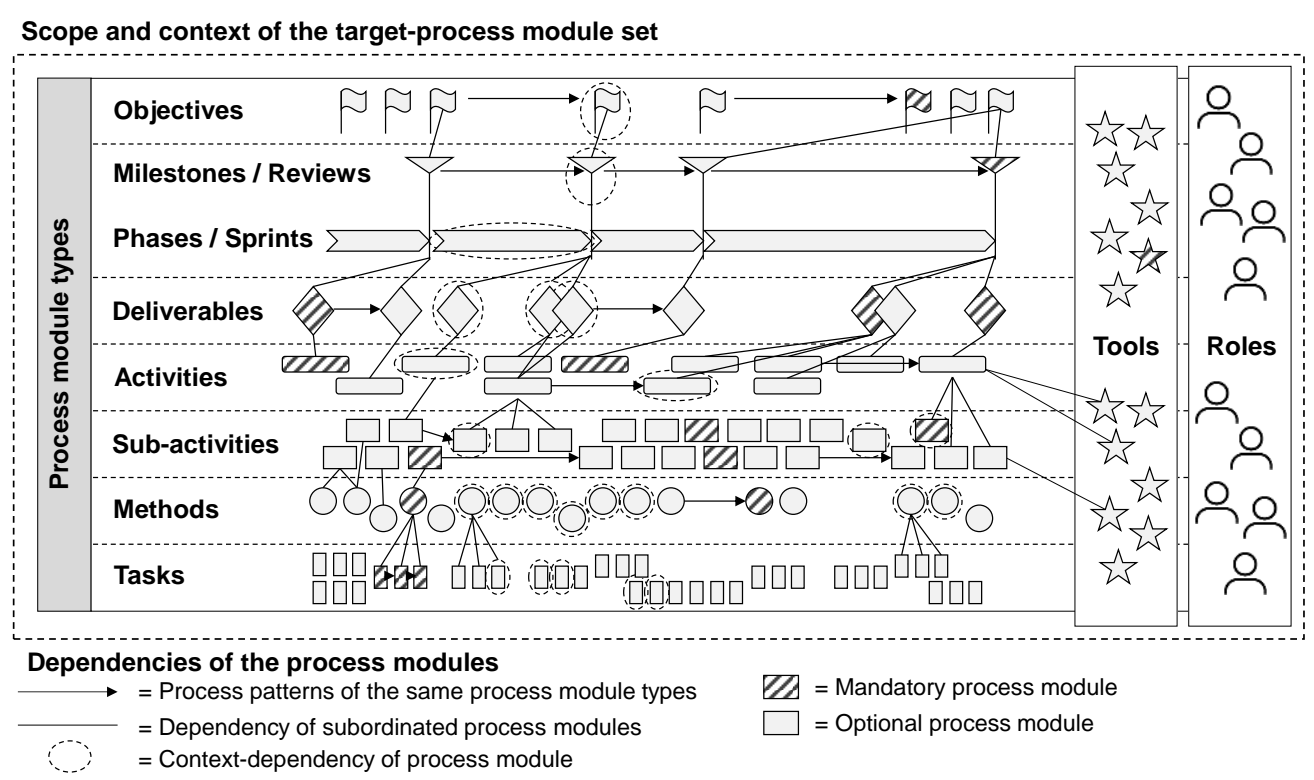

Figure 2. Model of the target-process module set

The different process module types include objectives that are part of the system of objectives (Ropohl, 2009) and describe the desired final state of the system in development at the end of the project or to another time within the project. Commonly, these objectives change during design projects. Milestones / reviews are synchronization points within a project to decide on the further course of the project. In practice, the project team defines necessary objectives and deliverables for each milestone in their project. An example for a milestone is the presentation of the project within a committee, a management decision or a sprint review. Phases / sprints define a specific time interval within the design project and are closed by a milestone or review. Commonly, phases / sprints are linked to objectives, deliverables and the product engineering activities. Deliverables can be derived from the objectives and describe objects or artefacts that should be available at a specific time, e.g. milestone or review, within the design project. Activities are "packages of work to be done" (Browning et al., 2006) to achieve the desired final state of the system in development. Depending on the field of application, an activity can be a product engineering activity, e.g. detecting ideas, building prototype or validating and verifying, as well as a problem solving activity, e.g. problem containment, alternative solutions or making decision, or can be a combination of product engineering and problem solving activities, e.g. finding alternative solution for product ideas. Sub-activities are manageable, smaller working units to realise a specific part of a deliverable. In agile managed design projects, sub-activities are equivalent to backlog elements, i.e. 
features, functions, requirements, enhancements or fixes (Schwaber and Sutherland, 2011). Methods are defined as scheduled procedures for achieving a previously defined goal (VDI 2223, 2004). Methods support the effective and efficient execution of sub-activities. Tasks are smaller working units or to dos that are necessary to execute a sub-activity. A typical task is the preparation of a method or the follow up after a method execution. Tools are aids to support the planning, controlling or the execution of design projects and thus support all types of process modules. Roles are used within the description of processes to assign responsibilities. Hence, a role can be assigned to activities and tasks that suit the capabilities and authorities of the role and can also be linked to all types of process modules.

The dependencies of the process elements include process patterns of the same process module types that describe a causal and logic correlation between single process elements of the same type. There are different types of process patterns, such as must-predecessors that are an essential input for the next process element, alternative process elements, or habits that are usual within a team or department. The dependency of subordinated process elements, describes the correlating suitability and necessity of subordinated process elements. For example, suitable methods for the sub-activity developing ideas can be different creativity methods, such as brainstorming or the 6-3-5 method, see also (Albers et al., 2014). The context-dependency describes the relevance and adaption of the process elements in a specific design context. Hence, it is possible that a process element is relevant for one project context but is irrelevant for another project context. Additionally, a process element can be adapted to a specific project context to ensure its applicability. An example for this dependency is that the sub-activity "creating CAD model of the system in development" is relevant for design projects with hardware components, but is not relevant within software projects.

To support the application of a target-process module set, the method for the instantiation and configuration of target-process suggestions for the creation and adaption of target-processes was developed (see Figure 3) and splits into five steps. In the first step, the project manager is asked to characterise his project context using an existing context-model, e.g. based on Gericke et al. (2013). In the second step, the relevant process elements of the target-process suggestion will be identified based on the project context. The project manager/team checks the relevant process elements and can adapt, i.e. add, change or delete process elements. Within the third step, the initial target-process is created, based on the previously defined relevant process elements and the dependencies of the target-process module set. The project manager/team now starts executing the design project (4.). Depending on the changing design situation, it is possible, that the target-process needs to be adapted during the execution. The context-model, the process elements, as well as the dependencies are required as input for the situationspecific adaption of the target-process. Depending on the volatility of the design situation, e.g. high frequently changing requirements, it can be necessary to repeat the forth step very often, sometimes on a daily basis. This enables a fast adaption of the target-process towards the changed design situation, which is especially relevant for projects that use agile project management methods. The fifth step includes the completion of the project and an evaluation of the target-process. Based on this information it is possible to learn for future design projects and to enhance the target-process module set.

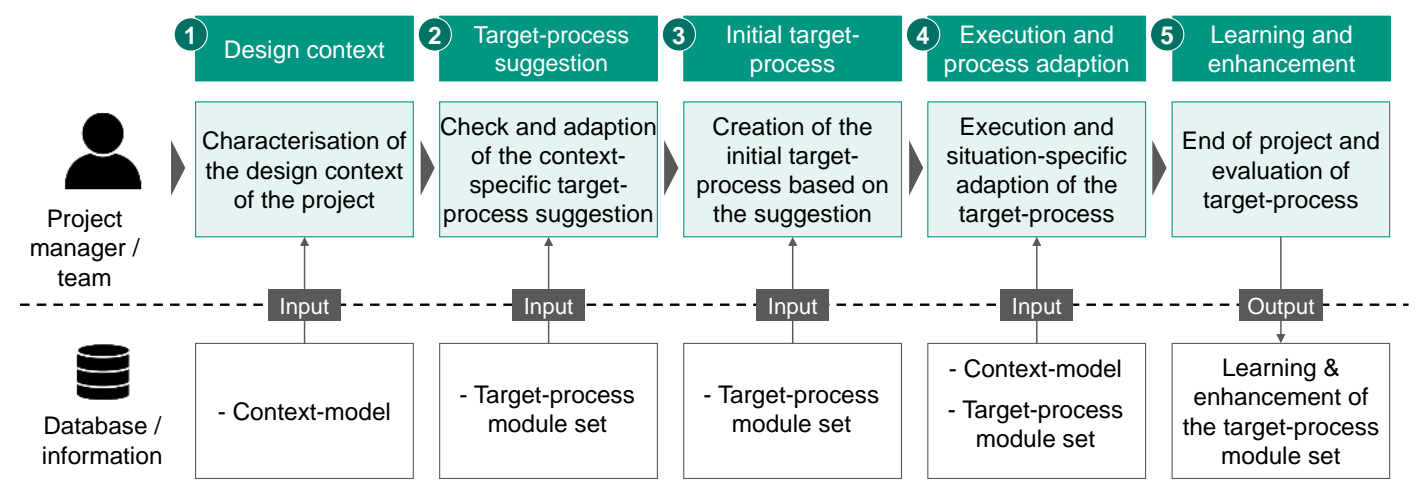

Figure 3. Method for the instantiation and configuration of target-process suggestions and the creation and adaption of a target-process

\section{CASE STUDY WITH PROJECT MANAGERS AT AUDI AG (DS-II)}

The objective of this case study was to evaluate the basic implementation of a target-process module set and to assess its added value. For the evaluation of the method at AUDI AG, it was first required to 
develop and prototypically implement a target-process module set. Figure 4 gives an overview on the used process module types and the corresponding dependencies of the process modules. The targetprocess module set includes three main objectives, 23 deliverables with 71 sub-deliverables, 208 subactivities (see also Wilmsen et al., 2019b for a list of the sub-activities) and $\sim 100$ methods. These process modules are linked hierarchically (dependency of subordinated process modules). For the objectives, the deliverables and sub-deliverables, a context-dependency was defined. The considered context-factors include the main result of the project, the main project objective, the development needs, e.g. software, mechanic, the domain and the project duration. Additionally, a situation-dependency was defined to enable the situation-specific method recommendation and adaption. Therefore, the contextfactors available resources, e.g. available time, participants, and desired method output were considered.

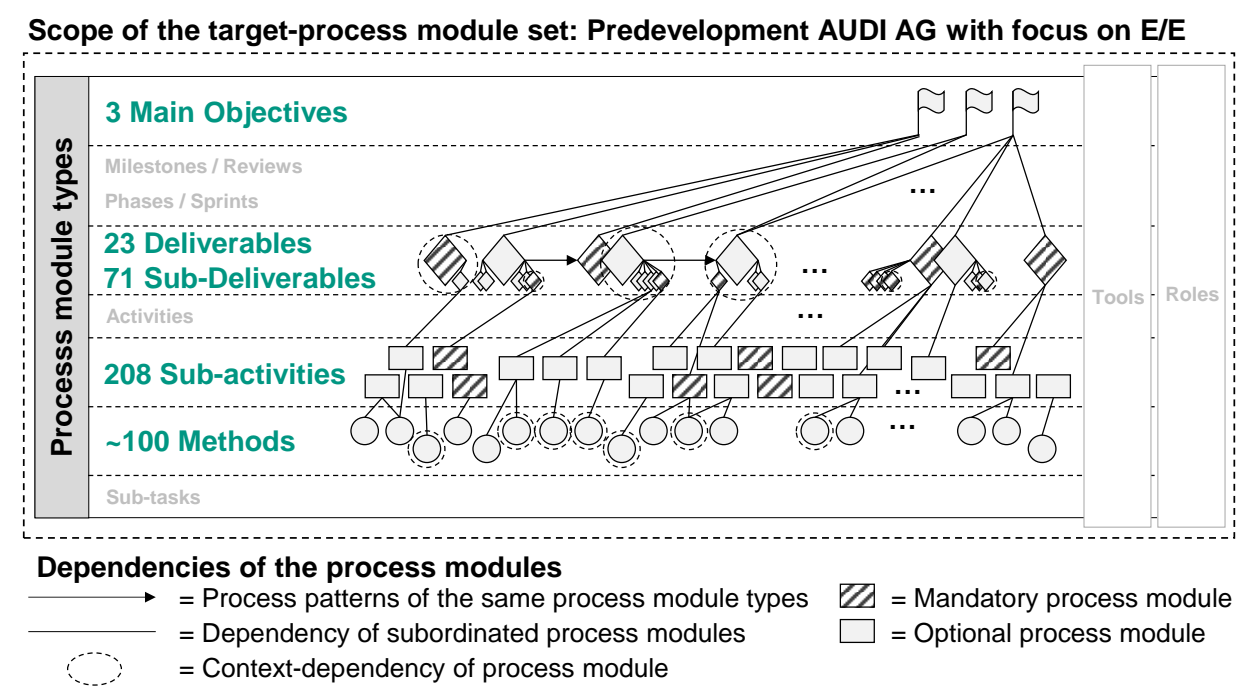

Figure 4. Target-process module set for the predevelopment at AUDI AG with focus on E/E

Based on the developed and prototypically implemented target-process module set, the method for the instantiation and configuration of target-process suggestions and the creation and adaption of a targetprocess was applied and evaluated at AUDI AG. Figure 5 gives an overview, how the five steps of the method (see Figure 3) were applied with the 21 project managers of different predevelopment departments during the application study.

\begin{tabular}{|c|c|c|c|c|}
\hline Design context & $\begin{array}{l}\text { Target-process } \\
\text { suggestion }\end{array}$ & $\begin{array}{l}\text { Initial target- } \\
\text { process }\end{array}$ & $\begin{array}{l}4 \text { Execution and } \\
\text { process adaption }\end{array}$ & $\begin{array}{l}\text { Learning and } \\
\text { enhancement }\end{array}$ \\
\hline $\begin{array}{l}\text { Characterise the } \\
\text { design context: } \\
\text { - Main result of the } \\
\text { project } \\
\text { - Main objective } \\
\text { - Development } \\
\text { needs (e.g. } \\
\text { software, mech.) } \\
\text { - Department } \\
\text { - Project duration } \\
\text { - Opt. competence } \\
\text { profile }\end{array}$ & $\begin{array}{l}\text { Long-term project } \\
\text { planning: } \\
\text { - Automated high } \\
\text { level planning for } \\
\text { project duration } \\
\text { - Adapt, insert, } \\
\text { remove } \\
\text { deliverables } \\
\text { - Assign resources } \\
\text { - Add milestones, } \\
\text { phases / sprints, } \\
\text { reviews }\end{array}$ & $\begin{array}{l}\text { Detail planning: } \\
\text { - Automated } \\
\text { planning of the } \\
\text { next quarter or } \\
\text { sprint } \\
\text { - Adapt, add } \\
\text { and/or remove } \\
\text { sub-activities } \\
\text { (opt. methods) } \\
\text { - Assign } \\
\text { resources }\end{array}$ & 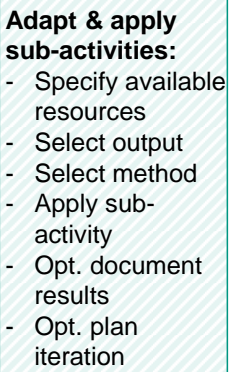 & $\begin{array}{l}\text { Document \& } \\
\text { evaluate: } \\
\text { - } \text { Automated } \\
\text { recording of } \\
\text { actual-process } \\
\text { - Evaluate target- } \\
\text { process } \\
- \text { Document best } \\
\text { practices and } \\
\text { lessons learned }\end{array}$ \\
\hline
\end{tabular}

Figure 5. Application of the method for the instantiation and configuration of target-process suggestions and the creation and adaption of a target-process at AUDI AG

The results of the application study are visualized in Figure 6. Hence, the majority of the participants agreed fully (43\%) or agreed mostly (43\%), that the method supports them to create a realistic targetprocess (A). Additionally, $43 \%$ of the participants fully agreed that the application of the method would result in more realistic target-processes than with their previous method (B). However, more than a quarter of the participants did not agree $(\sim 5 \%)$ or only partly agree $(24 \%)$ to this statement. The consecutive evaluation of the single functionalities $(\mathrm{C}-\mathrm{G})$ of the method did also show positive results. The third statement (C) referred to the long-term planning of the deliverables of the project and $\sim 38 \%$ of the participants agree, and $\sim 48 \%$ agree mostly, that this functionality supports them to create a realistic target-process. The detail planning of the methods and sub-activities (D) was evaluated as less supporting than the long-term planning. Here, 29\% agreed fully, 57\% agreed mostly, $9 \%$ agreed 
partly and $\sim 5 \%$ did not agree to the statement. The fifth statement (E) concerns the description and situation-specific adaption of the next sub-activity and method was agreed by $\sim 33 \%$ and partly agreed by $\sim 57 \%$ of the participants. The participants evaluated especially the integrated situation-specific method recommendation and adaption as valuable $(\mathrm{F})$. More than half of the participants $(\sim 52 \%)$ fully agreed to this statement and $\sim 43 \%$ agreed mostly. The last statement addressed the automated recording of the actual project course $(\mathrm{G})$ and $\sim 52 \%$ of the participants agreed that this statement supports them tracking the project progress and $\sim 29 \%$ agreed mostly. However, $\sim 14 \%$ of the participants only agreed partly and $\sim 5 \%$ did not agree to this statement. Overall, the majority of the participants expressed a positive impression of the approach and valued the approach as systematic, very stringent, extensive, but also as too rigid overall. However, there were multiple contradicting opinions of the participants. Some participants did for example perceive the approach as clear and easy, but others perceived it at the beginning as overwhelming and not clear. Additionally, the participants evaluated the approach as more flexible than conventional processes and appreciated, that the approach provides a new perspective on the process and supports the reduction of complexity and saves time, which leads to a more effective and efficient project execution. Furthermore, the semistructured interviews with the 21 participants uncovered the method recommendation, the structure of the approach and the resulting knowledge transfer as strengths of the approach. The participants evaluated the conscientious application of the approach, the quality of the database, the adaptability for a concrete project and the restriction of creativity during project planning and execution as weaknesses of the approach. As suggestions for improvements, most participants raised the proper implementation of the approach in an existing IT-Tool and wished additional functionalities, such as budget planning and tracking, automated project reporting, as well as the integration of more information from the superior vehicle development process, e.g. milestones of series development.

$\begin{array}{cccc}\text { I do not I partly } & \text { I mostly } & \\ \text { agree } & \text { agree } & \text { agree } & \end{array}$

\begin{tabular}{l} 
A. The method supports me during the creation of a realistic target- \\
process \\
$\begin{array}{l}\text { B. Due to the method, I am able to create a more realistic target-process } \\
\text { than with my previous method }\end{array}$ \\
\hline C. The long-term project planning (deliverables) of the method supports \\
me to create a realistic target-process \\
$\begin{array}{l}\text { D. The detail planning (sub-activities and methods) of the method } \\
\text { supports me to create a realistic target-process }\end{array}$ \\
$\begin{array}{l}\text { E. The description and adaption of the next sub-activity, incl. Method } \\
\text { recommendation supports me during the execution of the target-process }\end{array}$ \\
$\begin{array}{l}\text { F. The method supports me to select a suitable method } \\
\text { G. The automated recording of the actual-process supports me during } \\
\text { the tracking of the project progress }\end{array}$ \\
\hline
\end{tabular}

Figure 6. Results of the application study with 21 project managers at AUDI AG

\section{INTERVIEW STUDY WITH PROCESS AUTHORS (DS-II)}

The process authors had a positive impression of the approach presented and described it as a "cool approach" that is "very detailed", "very extensive" and "overall a great result". The approach has "potential to make work easier" for process authors and "opens up a degree of freedom that was not there before or [one] was not aware of". In addition, the approach was described as "a huge opportunity overall" and "should be applicable to organizations of different sizes". In addition, it was "good [rated] that a feedback loop is planned to further develop the approach". In addition, "[the approach] represents a process option for SPICE Level 3, [because] this [...] enables the requirements of SPICE Level 3 to be implemented". The "standardization of procedures" and the "consideration of standards" were seen as benefit of the approach, whereby "the process quality can be increased if correctly applied [...]". In addition, "the approach [...] is more extensive in process development" and thus "the target-process becomes more resilient". In addition, the approach can "reduce the adaptation effort of the target-process" and thus "make the project set-up easier", as well as "reduce errors in process adaptation". In addition, it was assessed as added value that the "approach is suitable for multi- 
project management" and can thus be used "for a pool of projects with different characteristics". In particular, "if all parameters [resp. Context factors] are known, then the approach is applicable to large area". This enables "standardized process control" to be implemented, which means, "fewer people are required to maintain the process". The most suitable areas of application for the approach are "divergent projects with different process requirements", which results in a "wide range between process requirements", for example with regard to quality and safety. The approach should be applicable in particular for "predevelopment projects", but also for "Level 3 SPICE for series development projects". In addition, especially "young project managers" can be supported by the approach. The approach could therefore be used "for almost every application area of development processes", since there is a "large variety of development projects" almost everywhere. In addition, the approach was assessed as "in principle compatible with agility", whereby agility alone is "difficult to map" using the target-process module set and the "fit of the organization to agility" plays a more important role. As suggestions for improvement, the process authors named mainly aspects that need to be checked and, depending on the objective and application of the approach, can be relevant to implement. Above all, the possibility of adapting the target-process module set and the target-process by project managers was questioned. It was suggested here that a process author or a process expert should carry out the review and adjustment of the target-process module set. The subsequent adaptation of the target-process by the project manager should include very restrictive degrees of freedom in order to ensure adequate process quality. Another suggestion for improvement was to add a best practice to show process authors how they can translate the theoretical approach into practice.

\section{DISCUSSION AND CONCLUSION}

The results of the case study are promising and reveal the potential, but also the weaknesses of the approach. However, some of the weaknesses relate to the prototypical implementation of the approach. Nevertheless, other weaknesses, such as the quality of the database need to be tackled for the further improvement of the approach. To answer RQ 1, the model of the target-process module set and the corresponding method for the creation of realistic target-processes by project managers was developed. The model incorporates the weaknesses of the compared approaches in section 2 to provide more realistic target-process suggestions. For the evaluation of RQ 2, a target-process module set was developed, prototypically implemented and initially evaluated within different predevelopment departments at AUDI AG. The evaluation results show, that the application of the developed approach does have a positive impact on the development of realistic target-processes. The interview study to evaluate RQ 3 also showed positive results from the perspective of a process author and also revealed further suitable fields of application for target-process module sets, such as SPICE Level 3 for series development. Based on these results, the research hypothesis cannot be falsified. Due to the small number of participants and the positive results it will be relevant for future studies to evaluate the approach within further projects, different fields of application and companies to increase the reliability of the evaluation results regarding the successful application of target-process module sets.

\section{ACKNOWLEDGMENTS}

This research has emerged from a three years research collaboration of KIT - Karlsruhe Institute of Technology and AUDI AG. Especially the active collaboration and participation of more than 120 project managers, engineers, as well as researchers contributed to the success of this research.

\section{REFERENCES}

Albers, A., Reiß, N., Bursac, N. and Breitschuh, J. (2016a), "15 Years of SPALTEN Problem Solving Methodology in Product Development", DS 85-1: Proceedings of NordDesign 2016, Volume 1, Trondheim, Norway, 10th - 12th August 2016, pp. 411-420.

Albers, A., Reiss, N., Bursac, N. and Richter, T. (2016b), "iPeM - Integrated Product Engineering Model in Context of Product Generation Engineering”, Procedia CIRP, Vol. 50, pp. 100-105. https://doi.org/10.1016/j.procir.2016.04.168

Albers, A., Reiss, N., Bursac, N., Urbanec, J. and Ludcke, R. (2014), "Situation-Appropriate Method Selection in Product Development Process - Empirical Study of Method Application”, DS 81: Proceedings of NordDesign 2014, Espoo, Finland 27-29th August 2014, pp. 550-559.

Bergqvist, J. and Gordani Shahri, N. (2018), 'Large-scale agile transformation - A case study of Volvo Cars' transformation process", 2018. 
Blessing, L.T.M. and Chakrabarti, A. (2009), DRM: A Design Research Methodology, Springer London, London. https://doi.org/10.1007/978-1-84882-587-1_2

Browning, T.R., Fricke, E. and Negele, H. (2006), "Key concepts in modeling product development processes", Systems Engineering, Vol. 9 No. 2, pp. 104-128. https://doi.org/10.1002/sys.20047

Bursac, N. (2016), Model Based Systems Engineering zur Unterstützung der Baukastenentwicklung im Kontext der Frühen Phase der Produktgenerationsentwicklung.

Cooper, R.G. (2016), “Agile-Stage-Gate Hybrids”, Research-Technology Management, Vol. 59 No. 1, pp. 2129. https://doi.org/10.1080/08956308.2016.1117317

Denning, S. (2020), "Why And How Volvo Embraces Agile At Scale”, Forbes, 26 January, available at: https://www.forbes.com/sites/stevedenning/2020/01/26/how-volvo-embraces-agile-atscale/?sh=4ce947014cf0 (accessed 21 November 2020.099Z).

Gericke, K., Meißner, M. and Paetzold, K. (2013), "Understanding the context of product development”, International Conference on Engineering Design, ICED13.

Götz, A. and Maier, T. (2007), "An adaptive product development process for engineers and industrial design engineers", Proceedings the 16th International Conference on Engineering Design, pp. 185-186.

Hallerbach, A., Bauer, T. and Reichert, M. (2008), Context-based Configuration of Process Variants, 3rd International Workshop on TCoB 2008. https://doi.org/10.5220/0001729600310040

Hollauer, C., Becerril, L., Kattner, N., Weidmann, D., Chucholowski, N. and Lindemann, U. (2017), "Adaptable Mechatronic Engineering Design Processes: Process Reference Model and Methodology”, International Conference on Research into Design. https://doi.org/10.1007/978-981-10-3518-0_52

Kumar, A. and Yao, W. (2012), "Design and management of flexible process variants using templates and rules", Computers in Industry, Vol. 63 No. 2, pp. 112-130. https://doi.org/10.1016/j.compind.2011.12.002

MacCormack, A., Verganti, R. and Iansiti, M. (2001), "Developing Products on "Internet Time": The Anatomy of a Flexible Development Process", Management Science, pp. 133-150. https://doi.org/10.1287/mnsc.47.1.133.10663

Meißner, M. and Blessing, L. (2006), "Defining an adaptive product development methodology", DS 36: Proceedings DESIGN 2006, the 9th International Design Conference, Dubrovnik, Croatia, pp. 69-78.

Nunes, V.T., Werner, C.M.L. and Santoro, F.M. (2011), "Dynamic process adaptation: A context-aware approach", in Shen, W. (Ed.), 15th International Conference on Computer Supported Cooperative Work in Design (CSCWD), 2011. https://doi.org/10.1109/cscwd.2011.5960061

Paasivaara, M., Behm, B., Lassenius, C. and Hallikainen, M. (2018), "Large-scale agile transformation at Ericsson: a case study”, Empirical Software Engineering, pp. 2550-2596. https://doi.org/10.1007/s10664-017-9555-8

Ponn, J., Braun, T. and Lindemann, U. (2004), “Zielgerichtete Produktentwicklung durch modulare Prozessstrukturen", 15. Symposium "Design for X".

Ponn, J. and Lindemann, U. (2005), "Characterization of design situations and processes and a process module set for product development", Proceedings 15th International Conference on Engineering Design.

Redding, G., Dumas, M., ter Hofstede, Arthur H. M. and Iordachescu, A. (2009), "Modelling Flexible Processes with Business Objects", in Hofreiter, B. (Ed.), IEEE CEC 2009 ; Vienna, Austria. https://doi.org/10.1109/cec.2009.39

Riesener, M., Dolle, C., Ays, J. and Ays, J.L. (2018), "Hybridization of Development Projects Through Processrelated Combination of Agile and Plan-driven Approaches", in IEEE IEEM2018: pp. 602-606. https://doi.org/10.1109/ieem.2018.8607323

Ropohl, G. (2009), Allgemeine Technologie: Eine Systemtheorie der Technik, KIT Scientific Publishing. https://doi.org/10.26530/oapen_422388

Schwaber, K. and Sutherland, J. (2011), The scrum guide.

VDI 2221 (2019a), VDI 2221: Blatt 1 Entwicklung technischer Produkte und Systeme - Modell der Produktentwicklung, Verein Deutscher Ingenieure e.V.

VDI 2221 (2019b), VDI 2221: Blatt 2 Entwicklung technischer Produkte und Systeme - Gestaltung individueller Produktentwicklungsprozesse, Verein Deutscher Ingenieure e.V.

VDI 2223 (2004), VDI 2223: Methodisches Entwerfen technischer Produkte; Systematic embodiment design of technical products, Verein Deutscher Ingenieure e.V.

Westerbuhr, F. (2020), "Airbus: Octane leverages SAFe methodology adoption to enhance DevOps and agile software/system development and testing environment", Micro Focus.

Wilmsen, M., Dühr, K. and Albers, A. (2019a), "A context-model for adapting design processes and methods", Procedia CIRP, Vol. 84, pp. 428-433. https://doi.org/10.1016/j.procir.2019.04.243

Wilmsen, M., Gericke, K., Jäckle, M. and Albers, A. (2020), "Method for the identification of requirements for designing reference processes", International Design Conference - Design 2020. https://doi.org/10.1017/dsd.2020.301

Wilmsen, M., Groschopf, L. and Albers, A. (2019b), "Establishing innovation: Relevant process steps for the automotive predevelopment process", R\&D Management Conference.

Wilmsen, M., Keiber, J. and Albers, A. (2019c), "Entwicklung von Erklärungsmodellen für die flexible Prozessund Projektplanung”, 15. Symposium für Vorausschau und Technologieplanung, pp. 513-527. 